Revista IBERC

v. 3, n. 2, p. 1-22, maio/ago. 2020

www.responsabilidadecivil.org/revista-iberc

DOI: https://doi.org/10.37963/iberc.v3i2.112

\title{
RESPONSABILIDADE MÉDICA E PRESCRIÇÃO OFF-LABEL DE MEDICAMENTOS NO TRATAMENTO DA COVID-19
}

\author{
MEDICAL LIABILITY AND OFF-LABEL PRESCRIPTION OF MEDICINES IN THE TREATMENT \\ OF COVID-19
}

\author{
Flaviana Rampazzo Soares ${ }^{i}$ \\ Luciana Dadalto ii
}

\begin{abstract}
RESUMO: Este artigo tem a finalidade de investigar responsabilidade médica na prescrição off-label de medicamentos para o tratamento de pacientes infectados pelo coronavírus. A análise desse tema passa, em sua trajetória investigativa, pela exploração conceitual da prescrição off-label, os limites dessa prescrição e a fronteira entre a licitude e a ilicitude nessa conduta, a verificar se existe diferenciação na responsabilidade por prescrição off-label em situação de pandemia e fora desta, no que concerne às suas consequências jurídicas no campo do direito de danos. Cuida-se de tema cuja atualidade e importância é acentuada nesse período excepcional de pandemia, cuja repercussão ainda será sentida nos Tribunais, em demandas indenizatórias que possam ser propostas por pacientes que tenham sofrido danos por experimentarem efeitos colaterais provenientes de uma administração medicamentosa baseada em uma prescrição médica dessa natureza. Buscarse-á igualmente apontar, no decorrer do texto, alguns dos diversos desafios a serem enfrentados, bem como as suas admissíveis soluções, as quais necessariamente passam pela indicação de alguns requisitos que podem ser aceitos como de justificação à prescrição off-label, para que seja possível identificar quando a conduta médica poderá ser considerada lícita ou ilícita.
\end{abstract}

Palavras-chave: Responsabilidade civil. Direito médico. Dano. Prescrição off-label. Pandemia.

\begin{abstract}
This article aims to investigate medical responsibility in off-label prescription of drugs for the treatment of patients infected with coronavirus. The analysis of this theme goes through, in its investigative path, the conceptual exploration of off-label prescription, the limits of this prescription and the boundary between lawfulness and illegality in this conduct, checking if there is differentiation in the off-label prescription liability in a pandemic situation and outside of it, with regard to its legal consequences in the field of tort liability. This is an important topic, whose topicality and importance is accentuated in this exceptional period of pandemic, whose repercussion will still be felt in the Courts, in claims for damages that may be proposed by patients who have suffered damage due to experiencing side effects arising from a drug administration based on a medical prescription of this nature. One will seek to point, during the text, some of the various challenges to be faced, as well as their possible solutions, which necessarily include the indication of some requirements that can be admitted as hypotheses of possible offlabel prescription, so that it is possible to identify when medical conduct may be considered lawful or unlawful.
\end{abstract}

Keywords: Civil liability. Medical liability. Damage. Off-label prescription. Pandemic.

SUMÁRIO: Introdução. 1. Definição de prescrição medicamentosa off-label e adoção dessa prática. 2. A prescrição off-label de medicamentos no direito estadunidense. 3. O uso off-label de medicamentos no

\footnotetext{
i Doutora em Direito pela Pontifícia Universidade Católica do Rio Grande do Sul (PUC/RS). Mestre em Direito pela mesma Instituição. Especialista em Direito Processual Civil. Advogada e Professora. ORCID https://orcid.org/0000-0002-5683-6603

ii Doutora em Ciências da Saúde pela Faculdade de Medicina da UFMG. Mestre em Direito Privado pela PUCMinas. Advogada e Professora. ORCID https://orcid.org/0000-0001-5449-6855
} 
direito brasileiro. 4. Responsabilidade médica e prescrição off-label em situação de pandemia. 5. Considerações finais. Referências.

\section{INTRODUÇÃO}

Os médicos são cotidianamente instados a apresentar respostas técnicas aos problemas de saúde que lhes são expostos. Nem sempre o aparato farmacológico posto à disposição destes é capaz, pela descrição direta da indicação em cada uma das suas respectivas bulas, de trazer uma resposta exata a um determinado problema de saúde detectado em um paciente.

As particularidades de cada doença e o perfil do paciente trazem um cenário específico que, muitas vezes, um único medicamento não é capaz de solucionar. Ainda, há várias situações nas quais a vivência profissional faz com que o uso de um determinado medicamento seja adaptado no decorrer do tempo pelas experimentações decorrentes do seu uso cotidiano. Cada situação traz em si a necessidade de uma resposta particular, embora grupos de casos possam apontar indicativos de caminhos a seguir.

Nesse cenário, a prescrição off-label assume protagonismo e, nela, constata-se que, na mesma medida em que há vários caminhos possíveis a trilhar para alcançar um determinado resultado, há, igualmente, desafios a superar. A pergunta a fazer é se um médico pode ou deve atuar no sentido de administrar ao paciente medicação, fora do que for estabelecido na bula.

Se essa conjuntura é complexa em tempos ditos "normais", em situação de pandemia a prescrição off-label parece ser o único caminho a ser trilhado, seja porque, de início, não há medicamento específico e tampouco tempo para desenvolvimento de tratamento típico de uma doença desconhecida, seja porque a premência exige que o médico atue para assistir ao doente, senão tratando a doença em si, ao menos suplantando ou mitigando seus efeitos, sintomas ou malefícios.

A inesperada pandemia da Covid-19 trouxe impactos inexoráveis à vida e ao direito, e a responsabilidade civil não está infensa às suas projeções. Assim, este texto tem como objetivo o de expor, ainda que de modo resumido, o significado da prescrição medicamentosa off-label, como ela é vista na literatura médica; de que forma ela é compreendida pelo sistema jurídico brasileiro nos atendimentos (e não nas pesquisas científicas); a validade jurídica desse meio de tratamento, os seus maiores méritos e alguns dos desafios enfrentados à sua admissão e concretização.

Em face dos limites inerentes a um artigo científico, não serão tratados aspectos de responsabilidade do Estado, apenas dos deveres médicos. Ainda, justifica-se a referência ao sistema estadunidense exposto no item n. 2 porque é no mencionado país que diversos debates sobre o uso da hidroxicloroquina vêm sendo travados com maior ênfase, inclusive com acentuada ingerência política. 
A partir disso, as perguntas a serem feitas, que compõem o problema da pesquisa, são duas, quais sejam:

(a) A prescrição medicamentosa off-label constituiu um meio eficiente e juridicamente válido, a ser empregado no atendimento dos pacientes da Covid-19?

(b) Quais são os principais benefícios e os maiores obstáculos à sua aplicação prática, sob o enfoque jurídico na área da responsabilidade civil médica?

Tem-se como hipóteses para a letra (a), que ela não seja admissível; que seja permitida sob determinadas condições ou que seja amplamente aceitável. E, para a letra (b), que ela seja de possível aplicação prática (total ou parcial) ou que os obstáculos sejam tamanhos que impeçam ou dificultem enormemente a sua aceitabilidade, gerando responsabilidade médica.

Para a construção da pesquisa apresentada, optou-se por utilizar como método de abordagem o dedutivo, assim como o dialético, de natureza aplicada e, na técnica de pesquisa, enfatiza-se a coleta doutrinária com abordagem qualitativa. $O$ método de procedimento é o documental.

Especificados esses aspectos iniciais, parte-se para o primeiro ponto a ser abordado neste texto, que é o significado da prescrição off-label.

\section{DEFINIÇÃO DE PRESCRIÇÃO MEDICAMENTOSA OFF-LABEL E ADOÇÃO DESSA PRÁTICA}

Delimitados os aspectos iniciais da pesquisa que envolve esse texto, parte-se para o primeiro ponto a ser abordado, que é o significado da expressão "prescrição off-label de medicamentos", a qual costuma ser empregada na literatura especializada do setor da saúde, no sentido de exprimir o uso de um medicamento homologado por órgão regulatório de vigilância sanitária, de forma distinta das suas indicações técnicas específicas, sustentado no direito do médico de exercer sua profissão com autonomia (Código de Ética Médica, Capítulo I, VII) e também na obrigação do médico de aprimorar continuamente seus conhecimentos e de indicar o procedimento adequado ao paciente, observadas as práticas cientificamente reconhecidas e respeitada a legislação vigente, não podendo praticar ou prescrever atos inúteis ou desnecessários.

Inclui-se no conceito prescrição off-label toda indicação médica de uso de um determinado medicamento, que seja diferente do que consta na sua bula. Isso inclui, v. g., a indicação terapêutica (p. ex., um medicamento cuja bula indica a sua administração para o tratamento da "doença x", que é particularmente receitado para a "doença y"); a posologia ( $p$. ex., a bula menciona um tratamento de " $x$ dias" e a recomendação médica foi de uso por " $x+2$ 
dias"); a administração para faixa etária distinta (p. ex., a bula menciona não ser indicada para pessoas com menos de 18 anos e há a prescrição para um adolescente de 16 anos), etc ${ }^{1}$.

Sabe-se que as pesquisas envolvendo pessoas vulneráveis é restrito (idosos, crianças, gestantes, etc.) e, para esse grupo, o emprego off-label de medicamentos tem tido ampla atuação, porque, em vários casos, não há opções de medicamentos com permissão de uso na bula, e, assim, os médicos prescrevem medicamentos permitidos em bula para outros grupos, adaptando a dosagem ou a periodicidade. Isso ocorre, e.g., com o uso de broncodilatadores inalatórios ou de anticonvulsivantes de uso adulto, por pacientes pediátricos.

Essa prática pode ocorrer para especificações com diferentes graus de risco, desde o mais leve (por exemplo, acrescentar ou excluir um dia de tratamento de um remédio antiinflamatório), até o mais intenso (um medicamento para a "doença x" empregado para o tratamento da "doença y").

A sua principal vantagem é a possibilidade de que ocorra a descoberta de novos usos para medicamentos já experimentados ${ }^{2}$. Com isso, amplia-se a abrangência das suas indicações, com o prévio conhecimento dos principais efeitos colaterais conhecidos e descritos na literatura farmacológica e vivenciados na prática clínica.

Por outro lado, o principal risco é o de que o fármaco não somente deixe de trazer benefícios, deixando de atender a determinada expectativa de eficácia, mas que produza efeito adverso, prejudicando o paciente que dele fez uso. Esse risco, admita-se, igualmente está presente na pesquisa de novos medicamentos. Outro problema é que o uso de medicamento fora das especificações da bula é uma espécie de "burla" do sistema de fiscalização e registro de farmacovigilância, assim como a escassa notificação de eventos adversos quando ocorre essa administração, que pode ocultar falhas de segurança e de eficácia do medicamento.

Embora essas informações possam trazer temor, tem-se que o uso off-label de medicamentos é prática recorrente na medicina, o que se vê, por exemplo, na administração da aspirina (ácido acetilsalicílico), que é um remédio para dores leves e moderadas, na profilaxia de

\footnotetext{
1 "Podemos, ainda, considerar que existe uma divisão da prescrição off-label na medida em que podemos ter uma recomendação de um medicamento para uma doença com sintomas completamente diferentes daquela para a qual o usos e encontra aprovado, ou, por outro lado, a prescrição de um medicamento para tratar uma doença ou condição para a qual tenha sido aprovado, mas alterando algumas especificações. Claro que, à partida, o primeiro tipo de caso é mais problemático e gera maiores dúvidas do que o segundo, que é, naturalmente, mais aceitável. No entanto, em termos práticos, não existe um estudo comprovado que possa assegurar que um dos casos seja mais seguro que outro". BARBOSA, Carla; MATOS, Mafalda Francisco. Prescrição off-label, direito à informação, consentimento informado e processo clínico eletrónico no direito português. Cadernos Ibero-Americanos de direito sanitário. Brasília. V. 5, n. 3, p. 157-179, jul./set. 2016. Trecho da p. 163.

2 "O uso off-label é comum no tratamento de doenças órfãs e de populações específicas como crianças, nas quais a indústria farmacêutica pouco investe em amplos testes para a fase de aprovação de medicamentos". (...) "Os opositores da prática de prescrição off-label argumentam que esta poderia ser utilizada como uma forma de burlar esse processo de aprovação de medicamentos lento e caro. Acrescentam que esse tipo de prescrição pode gerar efeitos perversos sobre o sistema regulador, permitindo que as empresas optem por registrar seus produtos pela via ou indicação que apresente maior facilidade durante os estudos clínicos, mesmo que já se saiba de antemão que o público alvo incluirá outras finalidades não contempladas nesses estudos. E tal fato pode acarretar descontrole ao sistema de saúde, em função de gastos em medicamentos e correlatos não previstos". NOBRE, Patrícia Fernandes da Silva. Prescrição off-label no Brasil e nos EUA: aspectos legais e paradoxos. Ciência \& Saúde Coletiva. Rio de Janeiro, v. 18, n. 3, p. 847-854, Mar. 2013.
} 
doença coronariana em pacientes diabéticos, ou de medicamentos inibidores da receptação de serotonina (v.g., fluoxetina) prescritos para tratamento da ejaculação precoce. A gabapentina inicialmente foi desenvolvida como anticonvulsivante e atualmente passou a ser utilizada para casos de neuropatia diabética. O conhecido botox (toxina botulínica), grandemente utilizado em procedimentos estéticos, foi criado inicialmente para o tratamento de estrabismo, sendo o seu uso estético descoberto posteriormente e por acaso. Na atualidade, o uso estético desse produto supera a sua indicação inicial de aplicação.

Admitidas essas considerações iniciais, cujo entendimento é essencial à compreensão do texto, tem-se que a resposta aos questionamentos expostos na introdução demanda a análise de um dos possíveis usos off-label acima expostos, que é a administração de medicamento com indicação terapêutica distinta daquela para a qual fora aprovado, tema cuja relevância de análise se acentua diante do cenário traçado a partir da pandemia causada pelo coronavírus, que não somente surge para embotar o sistema de saúde, como para desafiar os médicos, que se veem diante de uma grande incógnita, que é a nova doença, com contornos desconhecidos e muitas vezes avassaladores, que demandam respostas imediatas e, por vezes, criativas.

Os médicos são instados a, figurativamente, "tatearem no escuro", em busca de meios que, de alguma maneira, possam atenuar, refrear, mitigar ou curar a doença. A premência e a necessidade de respostas lança aos profissionais o desafio da descoberta de uma saída, a partir do que está ao alcance destes. Tendo em vista que o sistema farmacológico não consegue oferecer uma resposta efetiva e específica de forma rápida, o uso off-label de medicamento parece ser tentativa de descobrir uma solução ou um auxílio, porque a inclusão de um novo medicamento no mercado costuma ser cara, complexa e demorada, e os doentes de Covid-19 desse período não podem aguardar que ocorra todo o trâmite usual de ingresso de um medicamento no mercado.

Porém, admitir essa possibilidade não é o mesmo que franquear amplamente o uso indiscriminado dessa ferramenta, porque o paciente não pode ser tratado como objeto de pesquisa. Os parâmetros quanto ao que possa ser considerado como uso lícito ou ilícito da prescrição off-label no direito estrangeiro compõem o objetivo deste texto, o qual necessariamente passa por uma análise de direito estadunidense, que será exposto no próximo tópico.

\section{A PRESCRIÇÃO OFF-LABEL DE MEDICAMENTOS NO DIREITO ESTADUNIDENSE}

Conquanto se admita a impossibilidade de que este artigo contemple uma ampla pesquisa do tema no direito estrangeiro, algumas linhas podem ser traçadas, para que seja possível visualizar os principais apontamentos apresentados quanto a essa matéria nos EUA, que é o país em que se discute vivamente sobre o uso da hidroxicloroquina do tratamento da Covid-19, inclusive com apoio presidencial. 
Nos EUA, a National Commission for the Protection of Human Subjects of Biomedical and Behavioral Research ${ }^{3}$, debateu se o uso de um medicamento pode ser classificado como uma "prática médica" ou uma "ferramenta de pesquisa" e, para ela, a prática médica tem como finalidade o oferecimento de diagnóstico, de tratamento preventivo ou de terapia, diferentemente da pesquisa, que é realizada mediante o emprego de um método, utilizado para testar uma hipótese, a partir de um problema, e dela extrair conclusões.

Tendo em vista que, prática médica, há uma indicação para um caso de um paciente concretamente considerado e que, na pesquisa, se almeja contribuir para um conhecimento generalizável (uma pode servir à outra, mas são saberes empregados para distintos fins), pode-se afirmar que à prescrição off-label resta a classificação que mais se aproxima, que é a categoria de prática médica, e não de pesquisa, embora, a rigor, seja uma admissão não formalizada oficialmente e empregada fora do padrão prescrito no modelo utilizado para a sua autorização pelo órgão regulador específico.

De fato, na prescrição medicamentosa off-label, há uma intervenção terapêutica, com o propósito de atender a um doente determinado, em uma situação concretamente considerada. E, portanto, "a diferença substancial entre estes dois campos reside no interesse preponderante que o médico assume quando do aconselhamento feito para o uso do medicamento", de modo que, se estiver em pauta "um interesse supra-individual de obter conhecimento geral, estamos perante uma área experimental", enquanto que, se o objetivo for o de "obter um benefício directo para aquele paciente concreto, procurando uma efectiva melhoria da sua saúde e bem-estar, motivada tão só pelo interesse do doente", está-se diante do uso offlabel de medicamento ${ }^{4}$.

No âmbito jurisprudencial estadunidense, não há precedente judicial que tenha reconhecido a obrigatoriedade de prévio aviso, do médico ao paciente, que o uso de um medicamento prescrito seja off-label. Um precedente citado quando se trata do tema é o conhecido Canterbury v. Spence (1972), que trata de responsabilidade médica vinculada ao dever de aviso quanto aos possíveis riscos de uma cirurgia, a qual, no caso concreto, causou paralisia corporal parcial no paciente atendido (consequência que poderia atingir aproximadamente $1 \%$ dos casos submetidos a esse procedimento). A Corte de Apelação referiu que, embora um "paciente mediano" tenha "pouca ou nenhuma compreensão das artes médicas", o seu médico é capaz de fornecer o esclarecimento para que se chegue a uma decisão. Há necessidade de informação prévia para que seja emitido um consentimento válido, surgindo "a necessidade e, por sua vez, a exigência, de uma informação razoável do médico ao paciente, para tornar possível tal decisão", assim considerada aquela na qual uma pessoa

\footnotetext{
${ }^{3}$ National Commission for the Protection of Human Subjects of Biomedical and Behavioral Research: The Belmont report-Ethical principles and guidelines for the protection of human subjects of research. Federal Register. 1979, 44 (76): 23192-23197.

${ }^{4}$ BARBOSA, Carla; MATOS, Mafalda Francisco. Prescrição off-label, direito à informação, consentimento informado e processo clínico eletrónico no direito português. Cadernos Ibero-Americanos de direito sanitário. Brasília. V. 5, n. 3, p. 157-179, jul./set. 2016. Trecho da p. 164.
} 
razoável, ao decidir, provavelmente atribuiria significado ao risco ou conjunto de riscos existentes $^{5}$.

No case Klein v. Biscup (Ohio - 1996), afirmou-se que compete ao esculápio estabelecer a conveniência de uso off-label de dispositivos médicos, e que este não tem a obrigação de informar ao paciente sobre o status regulamentar do dispositivo perante a Food and Drug Administration (FDA). Porém, se negligentemente fizer uso off-label desses dispositivos, pode estar sujeito à responsabilidade em demanda promovida por quem for injustamente prejudicado6.

Esse precedente de Ohio, embora não exija do médico uma informação completa ao paciente de riscos potenciais, não o exime do dever de divulgar aqueles que sejam importantes, sendo isso considerado um padrão de atendimento desejável. Em 2018, o Tenth District Court of Appeals de Ohio julgou que um médico pediatra agiu negligentemente ao prescrever a um paciente de seis anos de idade o medicamento Lamictal (que na sua bula consta como fármaco com indicação antiepilética) para tratamento de transtorno bipolar. Com o uso do medicamento, houve o desencadeamento da atroz Síndrome de Stevens-Johnson, conhecida popularmente como a síndrome do esfolado-vivo, a ensejar quase um mês de internação hospitalar, com período em coma induzido, para o seu tratamento.

A Corte reputou o médico prescritor responsável por não ter divulgado aos genitores do paciente os riscos e benefícios da administração do medicamento quanto ao fim específico almejado (off-label). No julgamento, demonstrou-se que o profissional não informou à mãe do paciente os graves efeitos colaterais do medicamento, conhecidos como como "avisos de caixa preta" (que são riscos acentuados e graves que devem constar em destaque na bula) e os julgadores entenderam que, se essa informação tivesse sido transmitida pelo médico antes do início da terapia, a mãe não teria aceitado esse tratamento, porque uma pessoa razoável em circunstância idêntica ou similar teria decidido não usar o medicamento para tratamento de transtorno bipolar pediátrico, se os riscos e perigos fossem divulgados previamente. A condenação foi no montante de cerca de um milhão de dólares ${ }^{7}$.

Esse precedente indica que, para além de ser ou não um uso off-label de medicamento, é essencial que o esculápio indique ao paciente, ao seu representante ou ao seu assistente, conforme o caso, quais são os efeitos mais relevantes sob o aspecto qualitativo (mais comuns com repercussão séria) ou quantitativo (menos comuns, mas graves) e que possam impactar na decisão por tratar, não tratar, tratar parcialmente ou alterar o tratamento, o que vem ao encontro da doutrina estrangeira a respeito do consentimento do paciente.

\footnotetext{
${ }^{5}$ Canterbury v. Spence, 464 F.2d 772, 778 (D.C. Cir. 1972) é precedente igualmente descrito em: FADEN, Ruth R.; BEAUCHAMP, Tom L. A history and theory of informed consent. New Yortk: Oxford University Press. 1986. p. 133-134.

6 Martha L. Klein et al. v. Robert S. Biscup, D. O. et al. Case 1996-0798. In: http://www.supremecourt.ohio.gov/Clerk/ecms/\#/caseinfo/1996/0798. Acesso em: 17 maio 2020.

${ }^{7}$ R.T. v. Knobeloch, 10th Dist. no. 16AP-809, 2018-Ohio-1596, 111 N.E.3d 588, appeal not allowed, 153 Ohio St. 3d 1467, 2018-Ohio-3450, $106 \quad$ N.E.3d 65 (2018). Disponível em: https://law.justia.com/cases/ohio/tenth-district-court-of-appeals/2018/16ap-809.html. Acesso em: 18 maio de 2020.
} 
Nos EUA, a má-prática médica é considerada uma conduta prática profissional negligente, que depende da conjugação de quatro requisitos para a sua ocorrência: (1) um dever de cuidado previamente definido do médico prescritor frente ao seu paciente; (2) a violação desse dever, (3) a ocorrência de um dano que requeira compensação e (4) um nexo de causalidade a conduta negligente e o dano ${ }^{8}$.

Esse dever do médico é pautado pelo grau de cuidado admissível em situação semelhante, definido por duas perguntas:

1a) O médico agiu como a maioria dos profissionais atuaria em similar circunstância?

2a) A atuação do médico é razoável e admissível, considerando o padrão médico vigente?

Se a resposta for positiva aos dois questionamentos expostos, não será possível reconhecer responsabilidade médica. E, especificamente no tocante à prescrição off-label de um medicamento, pergunta-se se o médico que assim agiu estava se desviando do padrão de conduta adotado na área "fora da bula". Se a resposta for afirmativa, o profissional poderá ser responsabilizado.

Isso traz um obstáculo quanto à compreensão do padrão admissível de comportamento, em razão da dificuldade de verificação de um uso off-label não disseminado, porque um uso fora da bula não lesivo pode não ser um comportamento conhecido em larga escala, exceto quando ocorre a publicação de textos científicos relatando esse uso e os seus resultados positivos, a desencadear novos padrões admissíveis, envolvendo essa prática.

Assim, são propostos alguns questionamentos para verificar se essa prescrição é ou não admitida como uma prática adequada:

(a) o medicamento é aprovado pela FDA?

(b) o uso off-label foi submetido a uma revisão por pares?

(c) esse uso é necessário ao tratamento?

(d) esse uso não é experimental?

(e) a prescrição foi feita de boa-fé, no melhor interesse do paciente e sem intenção fraudulenta?

Se a resposta for positiva aos questionamentos expostos, então mitiga-se o risco da responsabilidade profissional ${ }^{9}$.

Mesmo que nos EUA não se considere o uso off-label de medicamento como uma questão a ser resolvida no âmbito regulatório (por estar no espaço de atuação e de avaliação médica), a FDA publicou em seu site a Guidance for Institutional Review Boards and Clinical Investigators, na qual afirma que os médicos que prescrevem medicamentos para uso off-label devem "estar bem informados sobre o produto, basear seu uso em uma fundamentação

\footnotetext{
${ }^{8}$ WITTICH, Christopher M., BURKLE, Christopher M., LANIER, William L. Ten common questions (and their answers) about off-label drug use. Mayo Clin Proc. Oct. 2012. V. 87. N. 10, p. 982-990 (trecho da p. 987).

${ }^{9}$ WITTICH, Christopher M., BURKLE, Christopher M., LANIER, William L. Ten common questions (and their answers) about off-label drug use. Mayo Clin Proc. Oct. 2012. V. 87. N. 10, p. 982-990 (trecho da p. 987).
} 
científica firme e em evidências médicas sólidas e manter registros do uso e efeitos do produto"10.

E a FDA, em razão da sua competência para regular o marketing e a distribuição de medicamentos nos EUA, permitiu que os fabricantes distribuíssem, aos prestadores de serviços de saúde, artigos de periódicos e capítulos de livros sobre usos off-label de medicamentos, desde que as informações fossem precisas; que a relação entre a distribuição das informações e o fabricante do medicamento patrocinador fosse divulgada e que o material publicado não fosse editado ou apresentado de forma abreviada ${ }^{11}$.

No entanto, o marketing off-label promovido por indústrias farmacêuticas tem sido uma das causas mais comuns de investigações fraudulentas do Medicaid ${ }^{12}$, sendo fonte de embates judiciais e de debates éticos. Em 2012, a fabricante Abbott pagou aproximadamente um bilhão e seiscentos milhões de dólares em multas por suposta comercialização off-label de ácido valproico (medicamento antiepilético) ${ }^{13}$. No mesmo ano, a fabricante Glaxo-SmithKline pagou três bilhões de dólares para solucionar uma disputa que envolvia alegado marketing ilegal do medicamento paroxetina, para uso em pacientes infantis, quando fora aprovado para uso em pacientes adultos; do antidepressivo bupropiona como auxiliar para perda de peso; além de relato falho quanto a informações de segurança sobre a medicação antidiabética cujo princípio ativo é a rosiglitazona (cujo uso acarreta alto risco cardiovascular e que, no Brasil, teve o seu registro cancelado pela Anvisa) ${ }^{14}$.

Com o fenômeno da Covid-19, a FDA emitiu um comunicado sobre a segurança dos medicamentos, datado de 24 de abril de 2020, tratando dos efeitos secundários conhecidos da administração da hidroxicloroquina e da cloroquina (usados nos EUA para prevenir ou tratar a malária). Os estudos clínicos ainda não são capazes de determinar o nível de segurança e de eficácia desses medicamentos para o tratamento da Covid-19, conquanto os graves efeitos colaterais cardíacos reportados no seu uso, sejam conhecidos e descritos nas respectivas bulas.

Assim, foi recomendado que os médicos façam prescrições individualizadas, se entenderem conveniente o uso desses medicamentos (após realizarem uma análise quanto a prováveis benefícios esperados, em comparação com os riscos possíveis), e que

10 "Off-Label" and Investigational Use of Marketed Drugs, Biologics, and Medical Devices Guidance for Institutional Review Boards and Clinical Investigators January 1998". In: https://www.fda.gov/regulatoryinformation/search-fda-guidance-documents/label-and-investigational-use-marketed-drugs-biologics-andmedical-devices. Acesso em: 17 maio 2020.

11 WITTICH, Christopher M., BURKLE, Christopher M., LANIER, William L. Ten common questions (and their answers) about off-label drug use. Mayo Clin Proc. Oct. 2012. V. 87. N. 10, p. 982-990 (trecho da p. 988).

12 KESSELHEIM, Aaron S.; MELLO, Michelle M., STUDDERT David M. Strategies and practices in off-label marketing of pharmaceuticals: a retrospective analysis of whistleblower complaints. PLoS Medicine. Apr. 2011. p. 1-9. V. 8. Issue 4.

13 ROEHR, Bob. Abbott pays \$1.6bn for promoting off-label use of valproic acid. BMJ. May 2012; 344:e3343.

14 Thomas K, Schmidt MS. Glaxo agrees to pay \$3 billion in fraud settlement. New York Times. July 2, 2012.http://www.nytimes.com/2012/07/03/business/glaxosmithkline-agrees-to-pay-3-billion-in-fraud-

settlement.html?pagewantedall.Accessed July 6, 2012. No mesmo sentido: WITTICH, Christopher M., BURKLE, Christopher M., LANIER, William L. Ten common questions (and their answers) about off-label drug use. Mayo Clin Proc. Oct. 2012. V. 87. N. 10, p. 982-990 (trecho da p. 989). 
permanentemente avaliem e supervisionem os pacientes, para mitigar riscos ${ }^{15}$. Conquanto possa ser visível a preocupação de que haja um risco de responsabilização de pacientes que possam ter lesões graves como efeitos colaterais decorrentes da ingestão desses medicamentos, objetiva-se com essa recomendação uma administração minimamente segura, assim considerada aquela na qual os benefícios de seu uso superam os seus riscos potenciais, com monitoramento.

Assim, pode-se afirmar genericamente que, nos EUA, a despeito de não existir um dever geral, atribuível ao médico, de divulgar a natureza off-label de um medicamento receitado, esse emprego não pode ser desarrazoado, sendo obrigatório ao médico informar ao paciente se o medicamento ou dispositivo a ser utilizado off-label fizer parte de uma investigação clínica ou outro estudo experimental ${ }^{16}$, bem como os seus riscos e perigos, que possam acarretar danos ao paciente.

E, embora ainda seja uma incógnita o caminho que as ciências da área da saúde e o direito trilharão em possíveis demandas futuras sobre o uso off-label da hidroxicloroquina e da cloroquina, ou de outros medicamentos, entende-se que o consentimento do paciente será um elemento essencial para verificação do conteúdo e do atendimento do dever de cuidado do médico, bem como do dever de informar, de modo que o médico deverá expor ao paciente, na medida do possível, os principais riscos e perigos inerentes e potencialmente envolvidos nos medicamentos utilizados no tratamento, para que o paciente possa decidir se deseja ou não a ele ser submetido e suportar seus eventuais efeitos colaterais ${ }^{17}$, mantido, sempre o dever de atuação profissional adequada, como será visto neste texto.

\section{O USO OFF-LABEL DE MEDICAMENTOS NO DIREITO BRASILEIRO}

No Brasil, em geral, a técnica de prescrição medicamentosa off-label não é regulamentada por lei. Tampouco é expressamente proibida, sendo amplamente utilizada na prática médica ${ }^{18}$, sendo possível visualizar a questão sob os enfoques regulamentar e jurisprudencial, o que será feito nos próximos dois tópicos.

No enfoque regulamentar, ver-se-á que há restrição relativa ao atendimento pelo SUS e por meio de planos de saúde, sendo mais utilizado fora desses âmbitos. E, na perspectiva

${ }^{15}$ A Comunicação referida está disponível no site da FDA: https://www.fda.gov/drugs/drug-safety-andavailability/fda-cautions-against-use-hydroxychloroquine-or-chloroquine-covid-19-outside-hospital-setting-or, acesso em: 17 maio 2020.

${ }^{16}$ CAVALLA, David. Off-label prescribing: justifying unapproved medicine. Oxford: Wiley Blackwell, 2015. p. 110.

17 SOARES, Flaviana Rampazzo. Consentimento informado: panorama e desafios. In: ROSENVALD, Nelson et al. (Coord.). Responsabilidade civil: novas tendências. 2. ed. Indaiatuba: Editora Foco, 2018. p. 491-501.

18 FERREIRA, Lilian de Abreu, et al. A alta prevalência de prescrições de medicamentos off-label e não licenciados em unidade de terapia intensiva pediátrica brasileira. Revista da Associação Médica Brasileira. São Paulo, v. 58, n. 1, p. 82-87, fev. 2012. 
jurisprudencial, verifica-se que a matéria tende a judicialização, diante da frequente negativa extrajudicial de fornecimento.

\subsection{Enfoque regulamentar}

De forma semelhante ao sistema estadunidense, há uma agência reguladora (Anvisa - Agência Nacional de Vigilância Sanitária), com ampla competência legalmente definida, a qual, dentre outras atividades, especifica a fiscalização, a regulamentação e o controle de produtos, substâncias e serviços de interesse para a saúde (conforme referido nos arts. $2^{\circ}$ e $3^{\circ}$ da Lei n. 9.782/1999) como atribuições da referida autarquia. A Anvisa trata, grosso modo, da segurança sanitária dessa cadeia produtiva, estando fora do âmbito de sua atuação o controle da prática médica (onde ocorre a prescrição medicamentosa), podendo apenas regulamentar e limitar o tipo de receituário a ser utilizado, de modo a permitir o controle do comércio de determinadas substâncias sob regime de vigilância sanitária.

No Sistema Único de Saúde (SUS), deve-se analisar a Lei n . 8.080/1990, a qual prevê que a assistência terapêutica consiste na "dispensação de medicamentos e produtos de interesse para a saúde, cuja prescrição esteja em conformidade com as diretrizes terapêuticas definidas em protocolo clínico para a doença ou o agravo à saúde a ser tratado" (art. 19-M).

No âmbito da referida Lei, tanto o protocolo clínico quanto a diretriz terapêutica são documentos que fixam "critérios para o diagnóstico da doença ou do agravo à saúde", o tratamento preconizado, principal e substitutivo (incluindo medicamentos apropriados e respectivas posologias); os mecanismos de controle clínico; o acompanhamento e a verificação dos resultados terapêuticos, que devem ser observados pelos gestores do SUS (arts. 19-N e 19O).

Na ausência de um protocolo ou diretriz, a dispensação deve observar as "relações de medicamentos instituídas pelo gestor federal do SUS" (art. 19-P).

$\mathrm{Na}$ circunscrição do SUS, a inclusão, a exclusão ou a modificação de novos medicamentos, produtos e procedimentos, bem como a constituição ou a alteração de protocolo clínico ou de diretriz terapêutica, são atribuições do Ministério da Saúde (Art. 19-Q).

Adicionalmente, o Decreto $n .^{\circ} 7.508 / 2011$ regulamenta a mencionada Lei $n .^{\circ}$ 8.080/90, dispondo sobre a organização do SUS, prevendo importante diretriz nos arts. 28 e 29 , cuja transcrição é feita abaixo:

Art. 28. O acesso universal e igualitário à assistência farmacêutica pressupõe, cumulativamente:

I - estar o usuário assistido por ações e serviços de saúde do SUS;

II - ter o medicamento sido prescrito por profissional de saúde, no exercício regular de suas funções no SUS;

III - estar a prescrição em conformidade com a RENAME e os Protocolos Clínicos e Diretrizes Terapêuticas ou com a relação específica complementar estadual, distrital ou municipal de medicamentos; e

IV - ter a dispensação ocorrido em unidades indicadas pela direção do SUS.

$\S 1^{\circ}$ Os entes federativos poderão ampliar o acesso do usuário à assistência farmacêutica, desde que questões de saúde pública o justifiquem. 
$\S 2^{\circ} \mathrm{O}$ Ministério da Saúde poderá estabelecer regras diferenciadas de acesso a medicamentos de caráter especializado.

Art. 29. A RENAME e a relação específica complementar estadual, distrital ou municipal de medicamentos somente poderão conter produtos com registro na Agência Nacional de Vigilância Sanitária - ANVISA.

O artigo 19-T da Lei $n^{\circ} 8.080 / 1990$, por sua vez, proíbe, "em todas as esferas de gestão do SUS" o pagamento, o ressarcimento ou o reembolso de medicamento, produto e procedimento clínico ou cirúrgico experimental, ou de uso não autorizado pela ANVISA, ou não registrado por esta.

Assim, no âmbito do SUS e sob o enfoque exclusivamente regulamentar acima exposto, a prescrição médica só pode ser feita se estiver em conformidade com a RENAME e os Protocolos Clínicos e Diretrizes Terapêuticas ou com a relação específica complementar estadual, distrital ou municipal de medicamentos; e se o uso for autorizado pela ANVISA, o que, em outras palavras, significa dizer que a prescrição off-label de medicamentos é restrita, o que vem a ser um desafio para o atendimento em tempos de pandemia, seja diante de uma necessidade de prescrição que pode não estar regulamentada a tempo, seja porque a própria regulamentação pode se tornar obsoleta rapidamente.

No setor dos planos e seguros privados de saúde, a regulamentação ocorre por meio da Lei n. 9.656/1998, a qual, em seu art. 10, incisos I e IX, proíbe "tratamentos ilícitos ou antiéticos, assim definidos sob o aspecto médico, ou não reconhecidos pelas autoridades competentes", na "cobertura assistencial médico-ambulatorial e hospitalar", assim como tratamentos experimentais. Por outro lado, como a maioria desses planos e seguros, no atendimento eletivo, não fornecem os medicamentos e não há um controle quanto ao conteúdo da prescrição, o médico pode muitas vezes fazer a prescrição off-label, sem que o plano ou seguro tenha conhecimento. E, quando o atendimento exige prescrição off-label na internação hospitalar, em muitos casos esse fornecimento é negado, cabendo ao paciente a busca da solução do impasse no Poder Judiciário (tema esse que não será abordado neste texto).

No atendimento clínico privado, este está sob a regulamentação geral e, nesse sentido não há controle quanto a prática da prescrição off-label, devendo-se observar o dever de cuidado, os princípios da ética biomédica e um standard tecnicamente adequado de atendimento.

A prática médica no Brasil é disciplinada pela Lei n. 12.842/2013, e vem sendo regulamentada pelo Conselho Federal de Medicina, notadamente por meio de resoluções. Afirma o CFM, no parecer n. 13/2004 - que a decisão médica de prescrever medicamentos com finalidades terapêuticas distintas das aprovadas pela ANVISA, é considerada como "pesquisa médica combinada com cuidados profissionais (pesquisa clínica), sendo obrigatória a obtenção do consentimento livre e esclarecido do paciente", referindo-se ao uso experimental de medicamentos, ou seja, aquele feito no âmbito de pesquisas clínicas realizadas com o objetivo de avaliar a segurança e a eficácia do medicamento mediante coleta e análise de dados. 
Já no parecer n. 2/16, o CFM posiciona-se favoravelmente à prescrição de medicamento para uso off-label, "enquanto as novas indicações não são aprovadas, seja porque as evidências para tal ainda não estão completas, ou porque a agência reguladora ainda as está avaliando", admitindo o seu uso, adicionalmente, quando o paciente apresenta "certa condição que, por analogia com outra semelhante, ou por base fisiopatológica" demande o uso de medicamento "fora da bula" para a qual o esculápio acredite que possa haver benefício ao paciente.

Citando o Parecer n. 482/13, o CFM refere que a prescrição off-label deve ser feita de modo pontual e específico, "por conta e risco do médico que o prescreve, e pode eventualmente vir a caracterizar um erro médico, mas em grande parte das vezes trata-se de uso essencialmente correto, apenas ainda não aprovado".

É curioso notar que o CFM, no mesmo parecer, adverte que os médicos "que assim procederem devem estar cientes das responsabilidades que assumem e do que thes recai como penalidades a que poderá responder", bem como da necessidade de "registro em prontuário das motivações para tal forma de conduta e do consentimento esclarecido do paciente ou, em razão de impedimento, de seu responsável legal". Ou seja, da mesma forma que, como Órgão de Classe, admite o uso, evidencia o risco deste uso, o que demonstra que se trata de terreno irregular, no qual o profissional precisa andar embasado na medicina baseada em evidências, a fim de minimizar os riscos para si e para o seu paciente.

No Parecer n. 8/2019, o CFM admitiu a possibilidade de uso off-label, para "controle da taxa de progressão de miopia em crianças", do colírio de atropina (indicado na bula para o tratamento de bracardia e como antídoto para intoxicação por organofosforados, carbamatos ou cogumelos muscarínicos). No mencionado parecer, adverte-se que esse uso é possível desde que o médico, oriente "familiares e pacientes sobre a necessidade da manipulação confiável do produto", esclarecendo "que esse, embora de comprovada eficácia e segurança, é um uso offlabel (sem indicação em bula)", o que enseja o "esclarecimento do fato ao paciente e a devida assinatura de Termo de Consentimento".

\subsection{Enfoque jurisprudencial}

No âmbito jurisprudencial, em pesquisa ${ }^{19}$ de ações judiciais que tratam desse tema, não foram localizados acórdãos que tratassem da responsabilidade do médico por danos a paciente em razão de efeito decorrente do uso prescrito de medicamento off-label. Os acórdãos que resultaram da busca são relativos a obrigatoriedade de fornecimento de medicações a

\footnotetext{
19 Pesquisa realizada no dia 16 maio 2020, no site www.tjsp.jus.br; na aba "jurisprudência", conjugando as palavras "medicamento", "off-label", "responsabilidade" e "médico". Foram consultadas as ementas disponibilizadas pelos sites mencionados, dos primeiros cem resultados de cada pesquisa. No site do STJ, foram utilizadas as palavras de busca "responsabilidade", "médico" e "medicamento" (www.stj.jus.br) dos anos de 2018 a 2020.
} 
pacientes, mesmo que sejam para uso off-label, em ações promovidas contra o Estado ou contra administradoras de planos de saúde ${ }^{20}$.

O Superior Tribunal de Justiça recentemente julgou Recurso Especial no qual uma consumidora com a doença de Parkinson realizou tratamento com base em medicamento (Sifrol, fabricado pelo Laboratório Boehringer Ingelheim do Brasil) prescrito pelo médico, cujo uso desencadeou como efeito colateral o jogo compulsivo, ocasionando perda de parte substancial do patrimônio da paciente, em bingos (quando o seu funcionamento era permitido no Brasil)21.

Embora houvesse um debate quanto a dosagem prescrita, constou na ementa do acórdão que a causação de efeitos colaterais ou reações adversas decorrente do uso de um medicamento "por si só, não configura defeito do produto se o usuário foi prévia e devidamente informado e advertido sobre tais riscos inerentes", permitindo que pudesse "decidir, de forma livre, refletida e consciente, sobre o tratamento que Ihe é prescrito, além de ter a possibilidade de mitigar eventuais danos que venham a ocorrer em função dele".

Especificamente quanto as indicações da bula, no acórdão constou que, a bula é "o mais importante documento sanitário de veiculação de informações técnico-científicas e orientadoras sobre um medicamento", mas que isso não pode fazer com que o fabricante se aproveite "da tramitação administrativa do pedido de atualização junto a Anvisa para se eximir do dever de dar, prontamente, amplo conhecimento ao público - pacientes e profissionais da área de saúde -, por qualquer outro meio de comunicação, dos riscos inerentes ao uso do remédio que fez circular no mercado de consumo".

Embora esse caso não trate da prescrição off-label de medicamento, nele consta que o fabricante deve estar permanentemente atento aos usos indevidos, aos estudos iniciados, em andamento e finalizados sobre os seus fármacos, e as consequências de sua administração, para que, de forma ostensiva, mantenha os médicos e os pacientes informados. E que o médico, tendo o dever de estar atualizado quanto aos principais estudos realizados na sua especialidade, publicados em periódicos reconhecidos, igualmente deve ser cuidadoso na prescrição, e diligente no acompanhamento do paciente.

Em outro acórdão, relativo a obrigação de fornecimento de medicamento por parte de plano de saúde, para uso off-label de paciente, em face de prévia indicação médica ${ }^{22}$, explicita-se que tratamento clínico ou cirúrgico experimental, é diferente de uso off-label de medicamento, porque no primeiro "o intuito da pesquisa clínica não é propriamente tratar, mas

${ }^{20}$ Como exemplifica a seguinte ementa: "PLANO DE SAÚDE - Cominatória c/c indenizatória - Sentença de procedência, para, confirmando a tutela de urgência, determinar à operadora de plano de saúde ré que custeie os medicamentos Nexavar (Sorafenib) 200mg e Rapamune (Sirolimo) 1mg; e condená-la a indenizar a autora, por danos morais, em $\mathrm{R} \$ 10.000,00$. Negativa administrativa de fornecimento do fármaco fundada no seu caráter off-label e na ausência de previsão no rol da ANS que não se sustenta. Infringência, ademais, às Súmulas nº 95 e 102 da Corte. Dano moral. Ocorrência. Quantum indenizatório bem arbitrado. Decisum mantido por seus próprios e jurídicos fundamentos, nos termos do art. 252 do Regimento Interno deste TJSP. Apelo não provido, com integração do julgado. TJSP. APC n. 110427717.2018.8.26.0100. $1^{\text {a }}$ Câmara de Direito Privado. J. em 08/05/2020. Rel. Des. Rui Cascaldi.

${ }^{21}$ STJ. 3a. Turma. REsp n. 1.774.372 - RS. Rel. Min. Nancy Andrighi. J. em 05/05/2020. DJE 18/05/2020. Disponível em: www.stj.jus.br. Acesso em: 18 maio 2020.

22 STJ. 4a. Turma. REsp n. 1.729.566-SP. Rel. Min. Luis Felipe Salomão. J. em 10/04/2018. Disponível em: www.stj.jus.br. Acesso em: 18 de maio de 2020 
alcançar resultado eficaz e apto ao avanço das técnicas terapêuticas atualmente empregadas, ocorrendo em benefício do pesquisador e do patrocinador da pesquisa", enquanto que no segundo, reconhecido como de uso "corriqueiro", "ocorre por indicação médica pontual e específica, sob o risco do profissional que o indicou". Esse emprego deve "ser respaldado em evidências científicas (clínicas)", e o seu objetivo é o tratamento de um paciente individualmente considerado, unicamente em benefício deste ${ }^{23}$.

No acórdão, defende-se a sua aplicação, "sob pena de se tolher o uso, para uma infinidade de tratamentos, de medicamentos eficazes para a terapêutica", pois "o medicamento off-label é fármaco com comercialização autorizada pela Anvisa e submetido ao Sistema Nacional de Farmacovigilância, cujo uso não fere as normas sanitárias" ${ }^{24}$. Refere-se que a própria Anvisa afirma que há hipóteses de uso off-label no Brasil, com indicação aprovada no exterior, que "há casos em que tais indicações nunca constarão na bula do medicamento, porque jamais serão ou poderão ser estudadas pelos vários ensaios clínicos necessários" e que o Conselho Federal de Farmácia afirmou que "quando um medicamento é aprovado para uma determinada indicação, isso não implica que essa seja a única possível e que o medicamento só possa ser usado para ela", pois um médico pode "querer tratar pacientes que tenham certa condição que, por analogia com outra semelhante, ou por base fisiopatológica, ele acredite possam vir a se beneficiar de um determinado medicamento".

A Ministra Maria Isabel Gallotti, em seu voto-vista (de divergência), mencionou que "uma vez registrado o fármaco na Anvisa, o médico não está restrito a ministrá-lo para as indicações contidas na bula, podendo utilizá-lo para outras finalidades", e que isso não representa um "salvo-conduto", pois segue responsável por "eventuais complicações causadas à saúde do paciente" 25 .

Ademais, reproduziu importante advertência feita pela Associação Brasileira de Medicina em Grupo (Abramge), no sentido de que a prescrição off-label "segundo pesquisas, é reflexo de manobras mercadológicas da indústria farmacêutica com a única finalidade de ampliar o consumo de seus produtos, sem observar os direitos fundamentais do paciente", feitas com base em "pesquisas que ficam aquém do padrão necessário para a aprovação dos órgãos regulatórios", mas que são divulgadas entre os médicos para estimular a prescrição, se aproveitando "do fato de os prescritores não serem obrigados a receitarem os medicamentos apenas para os fins para os quais foram aprovados" ao adotarem "estratégias que induzem o médico a prescrever para outros fins, onde a segurança e a eficácia não foram confirmadas".

23 Trechos das p. 13, 15 e 16 do acórdão.

Na doutrina, Ruzon esclarece que a prescrição off-label de medicamento é medida excepcional que "não ocorre dentro de um contexto de pesquisa médica, trata-se apenas da prescrição para hipótese não prevista no registro oficial", a qual se justifica "pelas circunstâncias clínicas individuais do paciente, por exemplo, a ocorrência de doença muito grave, de falha de resposta com a terapia convencional, e de existência de evidências de benefício terapêutico, não tem a finalidade de produção de novos conhecimentos médicos e incremento do conhecimento técnico da área". RUZON, Bruno Ponich. O uso offlabel de medicamento e o alcance da Lei n. 9.656/98. Revista Magister de direito empresarial, concorrencial e do consumidor. Porto Alegre. V. 9. N. 54. Ano IX. p. 73-85. Dez-Jan/2013.

24 Trecho da p. 16 do acórdão.

25 Trecho da p. 26 do acórdão. 
Assim, os laboratórios poderiam estar fazendo negócios e pesquisas ao mesmo tempo, e forma tecnicamente inapropriada e eticamente inaceitável ${ }^{26}$.

Assim, como conclusão parcial do tópico, é possível observar que o Poder Judiciário costuma afirmar que a prescrição off-label não é equivalente a tratamento experimental e que é admitida, desde que seja emitida por médico, amparado sob admissíveis critérios científicos, sob sua responsabilidade.

\section{RESPONSABILIDADE MÉDICA E PRESCRIÇÃO OFF-LABEL EM SITUAÇÃO DE PANDEMIA}

No âmbito do direito de danos, e especificamente sob o enfoque da responsabilidade da fabricante, é possível afirmar que, no Brasil, o paciente não pode responsabilizar o laboratório fabricante pela ineficácia do uso off-label para o tratamento de uma doença distinta daquela indicada na bula. Esse cenário se altera caso o próprio laboratório esteja direta ou indiretamente envolvido em pesquisas cujo resultado possam ter levado um médico a receitar um medicamento off-label ou cuja indicação terapêutica já ocorra em outros países regularmente ${ }^{27}$. Há, ainda, outras situações a diferenciar, como danos decorrentes de dosagem diversa, ou a sua administração para grupo distinto (por exemplo, um medicamento para adultos administrado a uma criança), o que deixará de ser abordado, em razão dos limites deste trabalho.

O que é diferente da análise da responsabilidade do prescritor, pois essa sim, pode ser questionada, como bem já admitiu o CFM:

\footnotetext{
${ }^{26}$ Ainda, conforme trecho das ponderações da Abrange, reproduzido na p. 39 do acórdão: "Prova disso é que, em janeiro de 2009, a Pfizer - gigante da indústria farmacêutica - foi condenada a pagar uma multa recorde nos Estados Unidos de 2.3 bilhões de dólares para pôr fim a uma demanda judicial. Conforme reportagem do jornal A Folha de São Paulo, a maior fabricante de remédios do mundo aceitou pagar a multa milionária em ação em que era acusada de fazer promoção ilegal de treze remédios, onde promoviam medicamentos para usos não aprovados na FDA (Agência Reguladora de Remédios e Alimentos nos Estados Unidos).(...) No mesmo ano de 2009, outra gigante da indústria farmacêutica, a Eli Lilly, foi multada em 1,4 bilhão por promoção ilegal do antipsicótico Planzapina. Segundo reportagem, durante o processo ficou comprovado que entre 1999 e 2003 a empresa treinou sua equipe de vendas para desconsiderar a legislação e promover o medicamento para usos não previstos em bula. A Eli Lilly declarou-se culpada, admitindo que sua estratégia de marketing foi ilegal".

Adicionalmente, Raposo assevera que: "O motivo pelo qual as empresas farmacêuticas não iniciam o processo para obtenção da autorização para aquele específico uso não está, em regra, relacionado com as características do produto, mas sim com estratégias de merchandising da empresa e com as suas políticas de gestão de risco (seja econômico, seja legal)". RAPOSO, Vera Lúcia. Da proteção dos consumidorespacientes na prescrição off-label. Revista de Direito do Consumidor. São Paulo. V. 110, ano 26, p. 163-186, mar.-abr. 2017.

A respeito do tema, veja-se, adicionalmente: SILVERMAN, Ed. Off-label marketing: free speech or illegal promotion? BMJ. Jan. 2013; 346:f793]. Disponível em: https://pubmed.ncbi.nlm.nih.gov/23341546/. Acesso em: 23 maio 2020.

${ }^{27}$ A indústria farmacêutica, em face do seu dever de cuidado, deve promover ensaios clínicos destinados à verificação de novas indicações que sejam ventiladas ou de alterações daquelas que constam em bula.
} 
O médico que prescreve medicamentos sem potencial de melhorar as condições de saúde do paciente, cuja eficácia terapêutica não foi comprovada, ou mesmo que prescreve medicamento capaz de agravar a condição clínica, lesa, diretamente, a saúde - direito constitucionalmente previsto e que deve ser resguardado - e causa dano passível de responsabilização, por não haver dúvidas do prejuízo sofrido ${ }^{28}$.

Nota-se, entretanto, que a responsabilidade do profissional no direito brasileiro, mesmo em contexto de pandemia, permanece sendo subjetiva. O que muda, em cenário de crise decorrente da pandemia, é o padrão admissível da conduta profissional na execução do ato médico.

Destarte, torna-se conveniente sugerir alguns parâmetros mínimos para, por um lado, permitir o exercício da liberdade de prescrição, com as correspondentes responsabilidades e prudência que circundam o seu exercício, mediante a indicação de um tratamento baseado nas evidências científicas e conformado particularmente às vicissitudes do paciente concretamente considerado.

Sabe-se que prescrição off-label "não conduz automaticamente a eventos adversos, nem necessariamente coloca em risco o consumidor-paciente", mas acentua os riscos do uso do medicamento justamente porque, na modificação sugerida pelo médico na prescrição, não houve a passagem pelos testes regulares, lembrando-se que a avaliação realizada para uma autorização considera apenas "os restritos usos do medicamento descritos no requerimento para concessão", "e não todas as suas hipotéticas utilizações, sendo que, na prática, essas outras utilizações se tornam cada vez mais frequentes" 29 .

Demanda-se, necessária e subsequentemente, uma divisão de dois cenários quanto ao uso off-label de medicamentos: em situações ordinárias da vida comum, nas quais é possível afirmar que o dever de cuidado do médico é mais acentuado ${ }^{30}$; e a situação atípica e extraordinária de uma epidemia com graves repercussões na saúde dos seres humanos, que demanda do médico decisões rápidas e sem a possibilidade de reflexões aprofundadas e validadas cientificamente da forma ideal.

$\mathrm{Na}$ situação de crise, como a ocasionada pela pandemia da COVID-19, não é possível exigir do médico que use medicamentos prescritos especificamente para essa doença, enquanto isso não existir. Por isso, deve ser considerado admissível que o médico prescreva o uso específico aos pacientes sob os seus cuidados, de medicamentos existentes e aprovados pelos órgãos regulatórios, necessariamente off-label, de acordo com a análise do caso concreto. Essa conduta será lícita se praticada de boa-fé, em dosagem adequada, com a segurança

${ }^{28}$ DADALTO, Luciana; SANTOS, Larissa M. Da responsabilidade civil do médico prescritor de medicamento não padronizado. In: AVANZA, CS; GEBRAN NETO, JP. Direito da Saúde em Perspectiva: judicialização, gestão e acesso. v. 3. Vitória: Editora Abrages, p. 140-141. 2018.

${ }^{29}$ RAPOSO, Vera Lúcia. Da proteção dos consumidores-pacientes na prescrição off-label. Revista de Direito do Consumidor. São Paulo. V. 110, ano 26, p. 163-186, mar.-abr. 2017.

${ }^{30}$ Exige-se que não exista medicamento autorizado para o uso específico; que haja evidências científicas que atribuam consistência terapêutica à prescrição; que essa prescrição seja a que atende da melhor maneira possível ao paciente em sua condição clínica; que haja o consentimento livre e esclarecido do paciente; que o paciente seja sujeito e não objeto do atendimento; que o paciente seja devidamente acompanhado; que a prescrição seja imediatamente suspensa diante de qualquer adversidade detectada, etc. 
admissível em uma situação atípica como essa pandemia e desde que não haja evidência científica comprovando o malefício, inclusive no que diz respeito ao Sistema Único de Saúde, caso haja omissão do Poder Público quanto à atualização da RENAME, dos Protocolos Clínicos e Diretrizes Terapêuticas e da ANVISA.

De outro lado, saliente-se que, caso o Poder Público publique uma determinação obrigando o médico a realizar determinada prescrição no âmbito do SUS, que seja tecnicamente considerada inadequada, e que venha a causar danos ao paciente, esses danos deverão ser imputados ao Estado.

Lembre-se que os médicos (e os profissionais da área da saúde, em geral) que atuam na "linha de frente" do atendimento aos doentes de COVID-19, estão não apenas sob pressão, mas, igualmente, em situação de exposição da própria saúde, ao realizar um trabalho com susceptibilidade biológica, em benefício da coletividade. Trata-se de um trabalho que pode ser considerado como altruísta, ainda que remunerado, a atrair o que os estadunidenses denominam de "good samaritan statutes", que é uma proteção dirigida a quem pratica trabalhos de assistência em saúde nas situações de emergência, e que tem a coragem tanto de assistir, quanto de decidir, o que exige proatividade e destemor. Assim, é justo que a análise da sua atuação (padrão de conduta admissível) não tenha o rigor que há no julgamento de uma conduta médica em situações ditas "normais" de atendimento, embora isso não signifique um laissezpasser para qualquer atitude deliberada por parte do profissional, a indevidamente transformar o paciente em objeto.

Tudo o que foi referido indica a necessidade de que sejam propostos requisitos a serem observados, em conjunto, para o uso lícito da prescrição off-label de medicamentos em situação de pandemia, abaixo listados:

a) que haja a constituição, pela Organização Mundial de Saúde, de situação de Emergência de Saúde Pública de Importância Internacional ${ }^{31}$.

b) que a doença nova, sem evidências científicas de terapêutica específica autorizada, ao tempo da administração off-label;

c) que haja indícios de benefício ao paciente;

d) que ocorra a imediata interrupção da prescrição, assim que surgirem evidências científicas que demonstrem que o malefício supera o benefício do uso off-label de um determinado fármaco;

e) que inexista norma técnica proibitiva, emitida pelos órgãos competentes no Brasil, quais sejam, a ANVISA e a Comissão Nacional de Incorporação de Tecnologias no SUS (Conitec);

f) que o paciente emita o seu consentimento livre e esclarecido, ou que exista autorização de quem o assiste ou representa, ambos após o devido processo informativodeliberativo, quanto aos riscos, benefícios, alternativas e custos envolvidos;

31 WORLD HEALTH ORGANIZATION. International Health Regulations. 3 ed. Disponível em: https://apps.who.int/iris/bitstream/handle/10665/246107/9789241580496-

eng.pdf;jsessionid=CB521F347363C19D62998CDB8CF0CBF3?sequence=1. Acesso em: 03 jun.2020. 
g) que a prescrição seja individualizada, devendo o médico analisar o caso concreto e não apenas o diagnóstico da patologia e

h) que ocorra a anotação justificada em prontuário, na qual o médico deve informar por que entende que aquele paciente pode se beneficiar da prescrição medicamentosa off-label, bem como o estado clínico no decorrer da administração medicamentosa e da internação.

É importante destacar que o comportamento admissível do médico é aquele vigente ao tempo da prescrição, e, caso essa administração medicamentosa dure tempo razoável, a conduta admissível passa a ser também aquela considerada correta durante todo esse período de administração. Ou seja, para uma doença nova como a COVID-19, um comportamento médico admissível no mês de fevereiro de 2020 , pode não ser o mesmo em setembro do mesmo ano, a depender da evolução das pesquisas quanto a forma de atendimento do paciente.

Indicados os pontos essenciais a respeito do tema, parte-se para as considerações finais.

\section{CONCLUSÃO}

Percebe-se que a pandemia traz desafios e demanda dos operadores do direito um trabalho de interpretação e de adaptação das normas existentes. Apresentaram-se, aqui, algumas reflexões sobre esse candente - e urgente - tema, reconhecendo a necessidade de obtenção de uma solução possível, que não negue o direito de autodeterminação do paciente, que não fira a liberdade do profissional e que não viole o princípio bioético da não maleficência.

Sabe-se que o balanceamento desses interesses é tarefa complexa e exige a compreensão da condição de vulnerabilidade técnica do paciente, o que deve ser levado em consideração na aferição de sua autodeterminação. Não se pode, sob o pretexto de proteger a autonomia do paciente, abrir mão do princípio hipocrático primum non noccere, motivo por que é inadmissível que a prescrição off-label seja tratada meramente como um ato de vontade unilateral do paciente, se isso não estiver de acordo com o estágio da ciência ao tempo do seu emprego. Da mesma forma, ainda em respeito ao princípio da autonomia, não pode o prescritor obrigar o paciente a aceitar a administração. Ou seja, está-se aqui, diante de uma efetiva tomada de decisão individualizada, fruto de uma deliberação do paciente que deve ser refletida, a partir de uma informação prévia de caráter técnico que lhe foi fornecida pelo médico que o assiste.

Neste cenário, respondendo ao questionado na letra (a) da introdução, afirma-se que é defensável que a prescrição off-label, quando seguir todos os requisitos aqui expostos, a não ensejar responsabilização civil do profissional; mas essa defesa não pode servir de salvo conduto para o profissional, que deve sempre se ater às evidências científicas seja ao tempo da prescrição, seja ao tempo da administração, ao melhor interesse do paciente a às normas éticas, jurídicas e regulatórias do Brasil, não sendo tolerável que a pandemia seja utilizada como 
pretexto para um novo episódio das "pílulas milagrosas", como ocorreu no fatídico caso da fosfoetalonamina.

E, por sua vez, quanto ao questionado na letra (b) da introdução, pode-se afirmar que a prescrição off-label traz o inegável benefício de emergir como opção aos profissionais da saúde no atendimento de doenças novas, ou nas quais não há medicação específica autorizada, mas, por outro lado, atrai o necessário cuidado tanto na prescrição, quanto na impossibilidade de que essa prática sirva para outros fins, que não o de atendimento ao paciente e aos seus legítimos interesses.

Adicionalmente, no âmbito da prescrição off-label, é possível concluir que há duas situações distintas a considerar: primeiro, o uso dessa ferramenta em situação de não pandemia, que deve ser considerado mais restrito, para o qual demanda-se que seja realizado de forma individualizada, apenas na ausência de medicamento específico e somente se o seu uso for considerado necessário, e não apenas conveniente, sob adequado consentimento do paciente ou autorização mediante representação ou assistência.

Caso o uso possa trazer risco ao paciente maior que o benefício esperado, não deverá ser admitido, devendo a sua administração ser acompanhada atentamente pelo médico, com suspensão imediata da medicação na hipótese de efeito adverso, a ser imediatamente comunicado ao laboratório e às autoridades competentes. Ademais, não se admitirá essa prescrição se houver disposição técnica proibitiva. Isso, no entanto, não retira a responsabilidade do médico decorrente do uso off-label de medicamento por parte do paciente quando presentes os requisitos da responsabilidade por danos, mesmo que haja consentimento do paciente, pois esse consentimento não retira do profissional o dever de atender às boas práticas médicas.

$\mathrm{Na}$ segunda situação, tem-se a hipótese de pandemia, que apresenta diferentes graus de avaliação quanto ao que seja considerado como conduta lícita, conforme seja mais recente ou menos recente: sendo mais recente, menos tempo houve para pesquisas quanto ao modo de atendimento e tratamento a ser dispensado ao paciente, motivo por que o médico tem maior liberdade na prescrição off-label, desde que obedecidos os requisitos mencionados no item n. 4 deste texto. A passagem do tempo, com o consequente avanço nos estudos e resultados de pesquisas, determinará alguns parâmetros mais seguros a serem adotados, os quais deverão ser observados pelo médico. Passada a pandemia, e indicado cientificamente um determinado padrão a seguir, este deverá pautar a conduta do esculápio. O critério da adequação é eficiente para determinar se a conduta do médico é ou não correta, e ele não responderá se atuar de acordo com o padrão admissível considerando outro profissional em situação equivalente.

Em ambos os casos, as anotações quanto ao percurso destes caminhos devem ser realizadas no prontuário ou na ficha do paciente, conforme o caso, a atuar como prova, memória e justificativa-base.

O médico não deve prescrever esperança. Ele prescreve fármacos, sob fundamento técnico, que tragam, no mínimo, um potencial e legitimamente esperado benefício ao paciente, o qual, nesse caso, é sujeito de atendimento, e não objeto de pesquisa. Utilizar-se da prescrição 
de um fármaco para alimentar uma ilusão de cura ou tornar o paciente um objeto de pesquisa, sem atender aos preceitos da ética biomédica e dos marcos regulatórios específicos é ato antijurídico e poderá ensejar responsabilização civil.

\section{REFERÊNCIAS}

BARBOSA, Carla; MATOS, Mafalda Francisco. Prescrição off-label, direito à informação, consentimento informado e processo clínico eletrónico no direito português. Cadernos lberoAmericanos de direito sanitário. Brasília. V. 5, n. 3, p. 157-179, jul./set. 2016.

CAVALLA, David. Off-label prescribing: justifying unapproved medicine. Oxford: Wiley Blackwell, 2015.

DADALTO, Luciana; SANTOS, Larissa M. Da responsabilidade civil do médico prescritor de medicamento não padronizado. In: AVANZA, CS; GEBRAN NETO, JP. Direito da Saúde em Perspectiva: judicialização, gestão e acesso. v. 3. Vitória: Editora Abrages, 2018. p. 140-141.

FADEN, Ruth R.; BEAUCHAMP, Tom L. A history and theory of informed consent. New Yortk: Oxford University Press. 1986. p. 133-134.

FERREIRA, Lilian de Abreu, et al. A alta prevalência de prescrições de medicamentos off-label e não licenciados em unidade de terapia intensiva pediátrica brasileira. Revista da Associação Médica Brasileira. São Paulo, v. 58, n. 1, p. 82-87, fev. 2012.

FOOD AND DRUG ADMINISTRATION. "Off-Label" and Investigational Use Of Marketed Drugs, Biologics, and Medical Devices Guidance for Institutional Review Boards and Clinical Investigators January 1998". Disponível em: https://www.fda.gov/regulatory-information/searchfda-guidance-documents/label-and-investigational-use-marketed-drugs-biologics-and-medicaldevices. Acesso em: 17 maio 2020.

KESSELHEIM, Aaron S.; MELLO, Michelle M., STUDDERT David M. Strategies and practices in off-label marketing of pharmaceuticals: a retrospective analysis of whistleblower complaints. PLoS Medicine. Apr. 2011. p. 1-9. V. 8. Issue 4.

NOBRE, Patrícia Fernandes da Silva. Prescrição off-label no Brasil e nos EUA: aspectos legais e paradoxos. Ciência \& Saúde Coletiva. Rio de Janeiro, v. 18, n. 3, p. 847-854, Mar. 2013.

NATIONAL COMMISSION FOR THE PROTECTION OF HUMAN SUBJECTS OF BIOMEDICAL AND BEHAVIORAL RESEARCH. The Belmont report-Ethical principles and guidelines for the protection of human subjects of research. Federal Register. 1979, 44 (76): 23192-23197.

OHIO. 1996-0798: Martha L. Klein et al. v. Robert S. Biscup, D.O., et al. Disponível em: http://www.supremecourt.ohio.gov/Clerk/ecms/\#/caseinfo/1996/0798. Acesso em: 17 maio 2020.

OHIO. R.T. v. Knobeloch, 10th Dist. no. 16AP-809, 2018-Ohio-1596, 111 N.E.3d 588, appeal not allowed, 153 Ohio St. 3d 1467, 2018-Ohio-3450, 106 N.E.3d 65 (2018). Disponível em: https://law.justia.com/cases/ohio/tenth-district-court-of-appeals/2018/16ap-809.html. Acesso em: 18 maio de 2020.

SILVERMAN, Ed. Off-label marketing: free speech or illegal promotion? BMJ. Jan. 2013; 346:f793]. Disponível em: https://pubmed.ncbi.nlm.nih.gov/23341546/. Acesso em: 23 maio 2020. 
SUPERIOR TRIBUNAL DE JUSTIÇA. 3a. Turma. REsp n. 1.774.372 - RS. Rel. Min. Nancy Andrighi. J. em 05/05/2020. DJE 18/05/2020. Disponível em: www.stj.jus.br. Acesso em: 18 maio 2020.

SUPERIOR TRIBUNAL DE JUSTIÇA. 4a. Turma. REsp n. 1.729.566-SP. Rel. Min. Luis Felipe Salomão. J. em 10/04/2018. Disponível em www.stj.jus.br. Acesso em: 18 de maio de 2020

RAPOSO, Vera Lúcia. Da proteção dos consumidores-pacientes na prescrição off-label. Revista de Direito do Consumidor. São Paulo. V. 110, ano 26, p. 163-186, mar.-abr. 2017.

ROEHR, Bob. Abbott pays $\$ 1.6 \mathrm{bn}$ for promoting off-label use of valproic acid. BMJ. May 2012; 344:e3343.

RUZON, Bruno Ponich. O uso off-label de medicamento e o alcance da Lei n. 9.656/98. Revista Magister de direito empresarial, concorrencial e do consumidor. Porto Alegre. V. 9. N. 54. Ano IX. p. 73-85. Dez-Jan/2013.

SOARES, Flaviana Rampazzo. Consentimento informado: panorama e desafios. In: ROSENVALD, Nelson et al. (Coord.). Responsabilidade civil: novas tendências. 2. ed. Indaiatuba: Editora Foco, 2018. p. 491-501.

TRIBUNAL DE JUSTIÇA DE SÃO PAULO. TJSP. APC n. 1104277-17.2018.8.26.0100. $1^{\text {a }}$ Câmara de Direito Privado. J. em 08/05/2020. Rel. Des. Rui Cascaldi. Disponível em: www.tjsp.jus.br. Acesso em: 18 maio de 2020.

THOMAS K, SCHMIDT MS. Glaxo agrees to pay $\$ 3$ billion in fraudsettlement. New York Times. July 2, 2012. Disponível em: http://www.nytimes.com/2012/07/03/business/glaxosmithklineagrees-to-pay-3-billion-in-fraud-settlement.html?pagewantedall. Acesso em: 18 maio 2020.

WITTICH, Christopher M., BURKLE, Christopher M., LANIER, William L. Ten common questions (and their answers) about off-label drug use. Mayo Clin Proc. Oct. 2012. V. 87. N. 10, p. 982-990.

WORLD HEALTH ORGANIZATION. International Health Regulations. 3. ed. Disponivel em: https://apps.who.int/iris/bitstream/handle/10665/246107/9789241580496-

eng.pdf;jsessionid=CB521F347363C19D62998CDB8CF0CBF3?sequence=1. Acesso em: 03 jun.2020.

Recebido: 05.06.2020

Aprovado: 20.06 .2020

Como citar: SOARES, Flaviana Rampazzo; DADALTO, Luciana. Responsabilidade médica e prescrição off-label de medicamentos no tratamento da COVID-19. Revista IBERC, Belo Horizonte, v. 3, n. 2, p. 1-22, maio/ago. 2020.

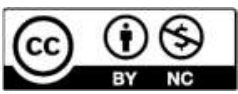

